\title{
Hallucinogen Rating Scale (HRS) - Versão brasileira: tradução e adaptação transcultural
}

\author{
Hallucinogen Rating Scale (HRS) - A Brazilian version: translation and cross-cultural adaptation
}

\author{
Suely Mizumoto ${ }^{1}$, Dartiu Xavier da Silveira ${ }^{1}$, Paulo César Ribeiro Barbosa², Rick J. Strassman 3 \\ 1 Departamento de Psiquiatria da Universidade Federal de São Paulo (Unifesp). \\ 2 Departamento de Filosofia e Ciências Humanas da Universidade Estadual de Santa Cruz (UESC). \\ 3 Escola de Medicina da Universidade do Novo México (University of New Mexico School of Medicine - UNM).
}

Recebido: 15/6/2011 - Aceito: 21/9/2011

\begin{abstract}
Resumo
Contexto: Existe um crescente interesse científico pelos efeitos de alucinógenos em geral e, particularmente, pelo uso religioso da bebida psicoativa ayahuasca no Brasil. Todavia, não há no Brasil um instrumento padronizado para avaliar os efeitos de alucinógenos. A Hallucinogen Rating Scale (HRS) é um questionário amplamente usado nos Estados Unidos e na Europa para avaliar os efeitos de diversas substâncias psicoativas, incluindo as alucinógenas. Objetivo: Traduzir e adaptar a HRS para o português brasileiro. Método: A adaptação foi realizada em três etapas: 1) os autores do artigo traduziram a HRS para o português, visando à elaboração de uma versão-síntese inicial; 2) foi feita retrotradução dessa versão para o inglês por dois tradutores independentes; 3 ) foi elaborada uma versão final em português brasileiro por um comitê de revisão. Esta versão final foi desenvolvida pela comparação entre as traduções iniciais e as retrotraduções, por um processo dialógico com o autor do instrumento. Resultados: Produção da versão final da HRS em português. Observaram-se as diretrizes para equivalência semântica e conceitual entre o português e inglês na descrição de estados subjetivos induzidos por alucinógenos. Conclusão: Uma versão brasileira da HRS instrumento largamente empregado em todo o mundo para quantificar os efeitos de psicoativos - fornece um instrumento sensível para a avaliação de efeitos de substâncias alucinógenas no Brasil.
\end{abstract}

Mizumoto S, et al. / Rev Psiq Clín. 2011;38(6):231-7

Palavras-chave: Ayahuasca, alucinógenos, dimetiltriptamina, escalas, validação.

\begin{abstract}
Background: There is a growing scientific interest in the effects of hallucinogens in general and the religious use of psychoactive brew ayahuasca in Brazil in particular. However, there is not yet a standard instrument used in Brazil to evaluate the effects of hallucinogens. The Hallucinogen Rating Scale (HRS) is a questionnaire widely used in the U.S. and Europe to evaluate the effects of several psychoactive substances, including hallucinogens. Objective: To translate and adapt the HRS to Brazilian Portuguese. Method: We followed three steps: 1) the authors of the article translated the HRS into Portuguese, in order to establish an initial version; 2) two independent translators back-translated this version into English; 3) a revision committee produced a final version of the Brazilian Portuguese version. This final version was developed comparing the initial translations and back-translations, through a dialogic process with the author of the instrument. Results: A final Portuguese version of the HRS, following the guidelines for semantic and conceptual equivalence between English and Portuguese to describe hallucinogen-induced subjective states. Discussion: A Brazilian version of the HRS - an instrument widely used throughout the world to quantify effects of psychoactive drugs - provides a sensitive instrument for evaluation of the effects of hallucinogenic substances in Brazil.
\end{abstract}

Mizumoto S, et al. / Rev Psiq Clín. 2011;38(6):231-7

Keywords: Ayahuasca, hallucinogens, dimethyltryptamine, scales, validation.

\section{Introdução}

Entre a década de 1950 e a de 1960, substâncias alucinógenas como o LSD e a psilocibina foram propostas, na América do Norte e na Europa, como adjuntos terapêuticos para tratamento de condições como ansiedade, depressão e dependência química ${ }^{1,2}$ e em investigações sobre experiências religiosas e bem-estar ${ }^{3}$. No início dos anos 1960, editoriais em prestigiosos periódicos acadêmicos começaram a questionar os métodos usados nas pesquisas com alucinógenos, acusando seus proponentes de parcialidade e viés decorrentes da autoexperimentação $0^{4,5}$. Tais críticas, somadas à publicidade sensacionalista recebida pela popularização do uso recreacional dessas substâncias e sua identificação com o movimento da contracultura, contribuíram para a interrupção desses experimentos no campo da saúde mental. Esse processo culminou na classificação dos alucinógenos, pelas autoridades norte-americanas, na categoria $\mathrm{I}^{6}$, reservada a substâncias de abuso, sem utilidade terapêutica ${ }^{7,8}$.
Três décadas se passaram até que se retomassem as investigações sobre potenciais terapêuticos dos alucinógenos em contexto experimental. Ensaios clínicos conduzidos ao longo da última década sugerem possibilidades promissoras dessas substâncias para o tratamento de transtorno obsessivo-compulsivo ${ }^{9}$, da ansiedade reativa em pacientes com câncer em estágio terminal ${ }^{10}$, da depressão ${ }^{11} \mathrm{e} \mathrm{da}$ dependência química ${ }^{12}$. Ademais, um rigoroso estudo experimental sugere que a psilocibina pode induzir experiências de tipo místico com mudanças positivas persistentes na espiritualidade e bem-estar psicológico ${ }^{13,14}$.

Dados esses resultados promissores, espera-se que esse tipo de pesquisa logo se desenvolva no Brasil. Neste país, ao interesse médico por essas substâncias soma-se uma importante dimensão cultural: o uso do psicodélico ayahuasca em contextos religiosos. Bebida originária da Bacia Amazônica, preparada a partir da decocção de folhas do arbusto Psychotria viridis e do cipó Banisteriopsis caapi, a ayahuasca contém os alcaloides DMT (, $\mathrm{N}$ - dimetiltriptamina), 
harmina, harmalina e tetra-hidroharmina. Protegida por lei e avaliada positivamente por comissões científicas interdisciplinares oficiais ${ }^{15,16}$, essa prática ritual envolve milhares de pessoas em religiões como a União do Vegetal e o Santo Daime ${ }^{17}$, que fazem parte do mosaico da diversidade religiosa brasileira ${ }^{18}$.

Não obstante a relevância médica e cultural que os alucinógenos vêm adquirindo no mundo e no Brasil ${ }^{19}$, não há, em nosso meio, um instrumento específico para avaliar efeitos subjetivos decorrentes dessa classe de substâncias.

A Hallucinogen Rating Scale (HRS) é um questionário autoaplicável, desenvolvido pelo Dr. Rick J. Strassman e colaboradores, em meados da década de 1990, na Universidade do Novo México, visando avaliar a amplitude de efeitos psicológicos decorrentes da DMT sintética, para o qual foi originalmente concebido. Segundo o autor, o desenvolvimento de uma nova escala para verificar os efeitos subjetivos induzidos pela DMT foi necessário, porque as escalas de avaliação de alucinógenos desenvolvidas anteriormente envolviam sujeitos selecionados entre a população carcerária, que não haviam sido previamente esclarecidos sobre a administração de alucinógenos, nem sobre seus efeitos. Os resultados desses procedimentos foram a elaboração de escalas negativamente enviesadas sobre os efeitos de substâncias alucinógenas, descrevendo-os como desagradáveis e de tipo psicótico 20 .

Portanto, a elaboração de uma nova escala, a partir de procedimentos menos propensos a tais vieses, mostrou-se necessária para a avaliação dos efeitos da DMT, sendo um dos objetivos do estudo Dose-Response Study of N, N-Dimethyltryptamine In Humans. II. Subjective Effects And Preliminary Results Of A New Rating Scale ${ }^{21}$.

A elaboração da HRS foi obtida mediante a combinação de dois métodos. No método clínico, as narrativas de 19 sujeitos sobre suas experiências com DMT free base foram organizadas em seis agrupamentos clínicos. Procurou-se também incluir efeitos comuns do DMT e de outros alucinógenos. A seguir, questões foram elaboradas para descrever esses agrupamentos em uma estrutura de "status mental" em termos descritivos e fenomenológicos: cenestesia (efeitos interoceptivos, i.e., visceral e cutâneo, ou seja, sentir-se corado, alteração no peso do corpo, estremecimento, mudança de temperatura); afeto (efeitos afetivos/emocionais como ansiedade, medo, euforia, vontade de rir ou chorar); percepção (experiências visuais, auditivas, gustativas e olfativas, ou efeitos visuais, presenças geométricas, ou sons soando diferentemente); cognição (alteração em processos ou conteúdos do pensamento, ou insights sobre a vida profissional ou pessoal); volição (uma mudança na capacidade espontânea para interagir consigo mesmo, com o ambiente ou com certos aspectos da experiência, i.e., perda de controle, impressão de sanidade ou insanidade e capacidade para se locomover, caso necessário) e intensidade (intensidade dos vários aspectos da experiência) ${ }^{21}$.

No segundo método, o desenvolvimento de agrupamentos baseou-se na análise dos componentes principais com a rotação de variância máxima, varimax, o que possibilitou que a computadorização dos dados gerasse fatores relevantes iguais em número dos agrupamentos clínicos. Uma descrição mais detalhada do tratamento estatístico pode ser obtida em Strassman et al. (1994) 21,22 .

A versão em inglês de 126 itens provou ser sensível a dosagens crescentes de DMT21, mas ainda não foi validada neste idioma. A versão atual da escala é composta de 100 itens, cuja administração leva de 5 a 10 minutos. Uma escala Likert, de 0 a 4 , é usada na resposta à maioria das questões. O 0 corresponde a "não mesmo", o 1 (um), a "muito pouco", o 2 (dois), a "moderadamente", o 3 (três), a "bastante" e o 4 (quatro), a "extremamente"21,22. Existem exceções para alguns itens que são redimensionados e invertidos para o cálculo final. Os escores para os diferentes agrupamentos são fornecidos pela soma dos escores obtidos para os itens individuais da escala, divididos pelo número de itens incluídos na dada escala ${ }^{22,23}$. Os agrupamentos clínicos são compostos por 4 questões para Intensidade, 13 para Cenestesia, 17 para Afetividade, 17 para Percepção, 12 para Cognição e 8 para Volição.

Das 100 questões, 29 ainda não estão posicionadas nos agrupamentos clínicos. Essa inclusão será realizada na próxima etapa do presente estudo de validação da escala em português, mediante análise fatorial quando da validação psicométrica do instrumento para as 100 questões existentes na HRS.

A confiabilidade e a validade convergente da escala com os 71 itens organizados nos agrupamentos clínicos foram investigadas na Espanha (Riba et al., 2001)23. Essas propriedades psicométricas foram testadas mediante dois procedimentos distintos. No primeiro procedimento (avaliação imediata), 75 usuários recreacionais da ayahuasca preencheram a HRS quatro horas após a ingestão do chá (71 questionários foram avaliados após a exclusão de quatro sujeitos). No segundo procedimento (avaliação tardia), 56 usuários de drogas diversas foram instruídos a preencherem a HRS e a versão de 49 itens da ARCI (Addiction Severity Index) conforme sua última experiência com substâncias alucinógenas. Por já ter sido validada na Espanha (Lamas et al., 1994)24, a ARCI foi usada como parâmetro de análise de validade convergente para a HRS. A ARCI é composta por cinco escalas: MBG (grupo morfina-benzedrina, medindo a euforia); PCAG (grupo pento-barbital-clorpromazina-álcool, medindo sedação); LSD (escala dietilamida de ácido lisérgico, medindo disforia e efeitos psicotomiméticos); BG (grupo benzedrina, medindo efeitos estimulantes) e A (grupo anfetamina, medindo sensibilidade para d-anfetamina).

A HRS mostrou-se sensível aos efeitos da ayahuasca (avaliação imediata) e aos efeitos de alucinógenos diversos (avaliação tardia). Na avaliação imediata, os coeficientes alfa para Percepção, Cognição, Cenestesia e Afeto foram adequados e aceitáveis, variando entre 0,81 e 0,88 . Entretanto, a Intensidade e a Volição não atingiram um valor adequado (0,33 e 0,51 , respectivamente). O mesmo efeito foi observado na avaliação tardia, com os valores para Percepção $(\alpha=$ $0.91)$, Cognição $(\alpha=0,86)$, Cenestesia $(\alpha=0,71)$ e Afeto $(\alpha=0,72)$ e os valores para Intensidade e Volição com $\alpha=0,50$ e 0,54 , respectivamente. A correlação mais alta foi entre Percepção e Cenestesia $(\mathrm{r}=0,74, \mathrm{p}<0,05)$, para o grupo da avaliação imediata, e para Afeto e Cognição $(r=0,70, p<0,01$, two tailed $)$, para o de avaliação tardia ${ }^{23}$.

As correlações convergentes significantes mais altas entre a escala ARCI e HRS ocorreram para LSD e Cenestesia $(r=0,33)$ e Percepção $(\mathrm{r}=0,28)$. O escore global da HRS também foi significantemente correlacionado com a escala LSD $(r=0,32, p<0,05)$. As escalas A e BG não se correlacionaram com os agrupamentos da HRS e com o escore global. A escala MBG mostrou uma correlação significante com Intensidade ( $\mathrm{r}=0,32 \mathrm{e}$ p negativamente com o escore global da HRS). Uma exceção ocorreu para duas correlações inversas significantes entre Volição e escalas A e BG $(r=-0,27$ e p provavelmente com Volição medindo uma dimensão independente não refletida pelas outras cinco escalas). Outra correlação não prevista existiu entre PCAG e agrupamentos da HRS, principalmente Cognição e Cenestesia, e também com o escore global. No entanto, PCAG e LSD compartilham um número de itens e são parcialmente relacionadas nas correlações já demonstradas do ARCI23.

Os autores deste estudo concluíram que a HRS apresentou graus aceitáveis de sensibilidade aos efeitos de alucinógenos, assim como de confiabilidade e validade convergente ${ }^{23,25,26}$.

A instrução para a aplicação da HRS consta em sua folha de rosto (Anexo I), existindo também instruções mais detalhadas que podem ser disponibilizadas para o aplicador interessado 22 .

Atualmente, a HRS é um dos instrumentos mais usados para avaliação dos efeitos psicológicos de outras substâncias alucinógenas diversas, como a ketamina ${ }^{12} \mathrm{e}$ a psilocibina ${ }^{13}$. Em nosso meio, a HRS poderá propiciar também a possibilidade de avaliar experiências religiosas de tipo místico, relevantes à investigação da espiritualidade, psicopatologia e saúde mental23,27,28.

\section{Método}

Para o processo de adaptação transcultural da HRS, adotou-se a orientação técnica de Guillemin ${ }^{29}$, composta pelas seguintes etapas:

1) Tradução: O instrumento foi traduzido do inglês para o português por dois tradutores independentes e fluentes em ambos os idiomas. A versão original em inglês e as duas traduções para o português foram comparadas por um dos tradutores e por um perito na avalia- 
ção de substâncias psicoativas. Almejou-se, nessa fase, um consenso na interpretação de termos para composição de uma única versão síntese da HRS, versão brasileira 1. Conduziu-se uma interlocução detalhada com o autor do instrumento, objetivando a adaptação de termos específicos usados para a avaliação da DMT em laboratório, para termos sensíveis ao uso da ayahuasca em contexto ritual. Nesse sentido, observou-se já nessa fase a "decentering technique", proposta por Guillemin ${ }^{29}$ para o comitê de peritos, como procedimento para melhorar a qualidade da adaptação transcultural. Nessa técnica, a versão original e final é considerada igualmente importante e suscetível às necessidades de modificações que podem ocorrer durante o processo de tradução e tradução reversa. Idealmente, a "decentering technique" é conduzida em estreita colaboração com o autor do instrumento, almejando-se, entre este e os tradutores, o consenso no estabelecimento de termos para expressão de um conceito.

2) Retrotradução: A versão brasileira 1 da HRS foi retrotraduzida por um norte-americano fluente no português brasileiro (RR, retrotradutor 1), que não tinha conhecimento prévio do instrumento. $\mathrm{O}$ autor do instrumento e um dos tradutores para o português conduziram a análise da retrotradução, objetivando a aproximação do ideal semântico e conceitual de cada palavra e expressão para os dois idiomas. Itens não aprovados pelo autor do instrumento passaram por nova tradução, a partir de suas sugestões. Esses itens passaram por outra retrotradução conduzida por outro retrotradutor brasileiro fluente em inglês. A seguir, procedeu-se a uma nova análise para equivalência semântica das duas retrotraduções com o autor do instrumento. Houve necessidade de expressar determinados termos e expressões idiomáticas em mais de uma palavra, procurando-se reproduzir no português o mesmo efeito emocional da versão original, tal como concebido pelo autor do instrumento.

3) Comitê de revisão: Um comitê de revisão composto por peritos nos efeitos de substâncias psicoativas, fluentes em inglês e português, fez a revisão final da HRS. Essa revisão baseou-se na seleção dos itens mais apropriados, rejeição dos inapropriados e inclusão de novos itens, realizados ao longo das várias traduções e retrotraduções. Também foi feita a revisão das instruções e seu formato. Esse processo seguiu as diretrizes de recomendação ${ }^{29}$ da Equivalência Conceitual para verificação da Equivalência Transcultural, entre a versão original e a final. Para tanto, observaram-se, entre a versão original e a versão brasileira, a Equivalência Semântica (equivalência de significado das palavras, gramática e vocabulário), a Equivalência Idiomática (expressões equivalentes para dimensões sociais e emocionais de significados semânticos não traduzíveis) e a Equivalência Experiencial (experiência habitual de sentimentos e de atividades equivalentes vividas na cultura-alvo). Ou seja, essa etapa baseou-se na definição da Equivalência Conceitual como a validade do conceito equivalente e existente numa cultura dada, e não somente seu significado semântico.

\section{Resultados}

O Comitê de Revisão manteve a denominação original da escala, acrescida da expressão "versão brasileira”: HRS - Hallucinogen Rating Scale: versão brasileira.

Abaixo, os itens coincidentes entre os dois tradutores para a primeira versão em português, aceitos pelo autor do instrumento na retrotradução. Para a versão-síntese, adicionaram-se os verbos "ter", "haver" e "sentir". Por exemplo, em vez de perguntar somente por "Dor de cabeça" seguido de uma interrogação, perguntou-se "Você teve dor de cabeça?". 3, 4, 5, 7, 9a, 14, 15, 18, 19, 22a, 24, 25, 27, 28a, 29, 31a, 33, 34a, 35, 36, 37, 38, 39, 40a, 41, 41a, 44, 45, 47, 50, 50a, 51a, 52, 52, 57, 58, 59a, 62, 63, 66b, 68a, 69, 71, 74, 75, 79, 80, 80a, $81,82 \mathrm{a}, 86 \mathrm{a}, 88,91,93$ e 98 .

Abaixo, itens não coincidentes entre os dois tradutores para a primeira versão em português. Nesses casos, para cada item, o comitê optou por uma das traduções para a versão a ser retrotraduzida. Esses itens não foram alterados pelo autor do instrumento: $7 \mathrm{a}, 10,11,16$, $17,20,21,22,23,26,27 \mathrm{a}, 32,40,42,46,48,49,51,54,55,56,59 \mathrm{a}$, $60,60 \mathrm{a}, 61,62,64,65,66,66 \mathrm{a}, 67,68,68 \mathrm{a}, 70,72,73,76 \mathrm{a}, 77,78,81 \mathrm{a}$, $82,83,84,85,86,87,89,90,90$ a, $92,95,96$ e 100.
A seguir, são enumeradas as questões que demandaram mais discussão entre os tradutores e o autor do instrumento, para chegar a versões finais mais próximas.

Questão 1: Tendo em vista a utilização futura da HRS para outras substâncias psicoativas que não a ayahuasca, o comitê e o autor do instrumento decidiram manter a questão em aberto, sem a especificação da substância psicoativa experimentada para verificação dos efeitos avaliados pela escala para aplicação futura, de forma genérica.

Questão 2: Substituiu-se o termo "rush", apropriado aos efeitos da DMT sintética e ao idioma inglês, pela questão "Como você sentiu a rapidez e a força dos efeitos chegando?", adequada ao uso da ayahuasca em contexto ritual e ao idioma português.

Itens 6, 12, 13, 43, 53: Manteve-se, a pedido do autor, a tradução literal do original em inglês, pois, segundo ele, as versões retrotraduzidas distorciam o sentido original das questões.

Questão 8: Electric/tinglingfeeling são expressões compreensíveis em inglês, que foram aproximadas, segundo recomendação do autor do instrumento, na versão inicial antes da retrotradução, para "Você sentiu agulhadas/alfinetadas e/ou uma pequena sensação elétrica/ eletricidade?".

Questão 9: O autor do instrumento solicitou substituição, na retrotradução, da expressão Pressão no peito ou na barriga (Pressure on the chest or belly) por Pressão dentro do peito ou na barriga (... inside the chest or belly).

Questão 13: O autor do instrumento solicitou substituição, na retrotradução, de "Sentiu o coração falhando ou batendo irregularmente?" (“Felt heart skipping beats or beating irregularly?") para "Sentiu o coração batendo irregularmente? (beating irregularly).

Questão 28: Para a expressão At ease, foram necessárias várias aproximações em todas as fases da tradução, retrotradução e diálogos entre o comitê de revisão e o autor do instrumento, para alcançar a expressão correspondente mais adequada ao português: "Você se sentiu à vontade?".

Questão 30: Excited. O comitê de revisão explicou ao autor do instrumento sobre vários termos em português que poderiam ser equivalentes. Decidiu-se por "Você se sentiu animado, disposto, entusiasmado?".

Questão 31: Awe. Foi adotado o mesmo procedimento da questão anterior. Decidiu-se por "Você se sentiu em estado de reverência ou em deslumbramento?".

Questão 34: "Change in feeling about sounds in room?". O autor do instrumento assinalou que essa questão objetiva avaliar a resposta emocional aos sons. A questão foi traduzida em termos finais para o português como: "Você sentiu uma mudança no modo pelo qual você respondia "emocionalmente" (sentia/experimentava) aos sons?".

Na questão 36a, para loving, o autor do instrumento optou pela expressão cheio de amor (full of love). Não foi identificada uma palavra equivalente em português para a tradução.

Questão 55a: Sugestão do autor: sons soavam mais claros, ou menos claros.

Questão 59: O autor do instrumento solicitou alterar "Change in brightness of objects in room?" para "The objects in the room had a different brightness than usual?", que, na versão final em português, foi vertida para "Os objetos da sala tinham um brilho diferente do habitual?".

Questão 76: “Change in strength of sense of self?”. Optou-se, após a retrotradução, em consenso entre o comitê e o autor do instrumento, por uma modificação de sentido, com uma nova compreensão semântica e conceitual, objetivando uma tradução mais aproximada do que se propunha a avaliar na versão do inglês original. Na versão final em português, este item foi traduzido como "Você sentiu uma mudança na percepção de 'como você é??'.

Questão 88: “More sane, less sane, or both?". O autor do instrumento solicitou adicionar o termo mentalmente antes de mais/menos são, tornando-se a questão formulada, portanto, como "Mentalmente mais são, mentalmente menos são, ou ambos?". 
Questão 94: In control. Foi realizada uma aproximação dessa expressão para "Você foi capaz de controlar a si mesmo e a situação (sob controle)?”.

Questão 97: “Waxing and waning of the experience?”. Na versão 1, enviada para retrotradução como "Você sentiu que houve um movimento de ascensão e declínio na experiência?", houve uma solicitação do autor do instrumento para essa questão avaliar a experiência ocorrendo em "ondas" repetitivas, refletindo a ascensão e o declínio dos efeitos subjetivos do psicoativo. Seguindo-se as orientações, a questão foi retrotraduzida para "Did you feel that there was a repetitive ascending and descending quality in the experience?". Na versão final em português, obteve-se "Você sentiu que havia ondas repetitivas de ascensão e de declínio (efeitos da substância) na qualidade de sua experiência ao longo do processo?".

Questão 99: High. O autor do instrumento sugeriu acrescentar a descrição da presença de um estado de intoxicação para tornar mais claro o sentido da questão. Na tradução, optou-se pelo uso de uma expressão popular para designação de um estado de consciência alterado pelo uso de um psicoativo: "ligado". Para a forma final em português, obteve-se: "Sentiu-se 'ligado' (ou seja, estar sob o efeito de uma substância, com um estado alterado de consciência)?".

Abaixo, as traduções para as respostas às questões: Not applicable: Não aplicável; Not effect: Sem efeito; Not at all: De modo nenhum; Lightly: Levemente; Moderately: Moderadamente; Very much: Muito; Extremely: Extremamente; Never again: Nunca mais; Don't know: Não sei; Eyes closed: Olhos fechados; None seen: Nada visto.

As instruções de preenchimento foram revistas pelo autor do instrumento (vide apresentação do instrumento em Anexo I).

\section{Conclusão}

Nos últimos anos, observa-se um crescente interesse pelas substâncias alucinógenas. Além de seu potencial de abuso, esse interesse vem sendo justificado pelo potencial terapêutico de tais substâncias e, no Brasil, pela relevância cultural do uso da ayahuasca em contexto ritual e religioso. Portanto, faz-se necessário neste país um instrumento confiável para avaliação dos estados de consciência induzidos por essa classe de substâncias.

Uma medida-padrão para estudo nacional e internacional dos mesmos fenômenos em termos transculturais facilita as pesquisas comparativas em ensaios clínicos e pesquisas experimentais ligadas às áreas da psicofarmacologia, neuropsicologia, psiquiatria transcultural e psicologia.

Para investigar a validade de um instrumento na área de saúde mental, devem-se comparar seus resultados com os de um padrão de qualidade reconhecida ("padrão-ouro"), até então inexistente em versão brasileira. Nesse sentido, são apresentadas a seguir a tradução e a adaptação transcultural da HRS - versão brasileira (Anexo I), que inaugurará esse padrão-ouro para comparações futuras.

\section{Agradecimentos}

Ao Dr. Rick J. Strassman, pela permissão dada para o início do processo de validação, por sua colaboração na tradução e adaptação transcultural deste instrumento HRS - versão brasileira, bem como por sua participação extremamente enriquecedora durante todo o processo da busca da equivalência semântica do instrumento. Gratidão ao Dr. Ronald Rosen e à Maria Silvia M. Pires, pela valiosa colaboração quanto à tradução.

\section{Referências}

1. Grinspoon L, Bakalar J. Psychedelic drugs reconsidered. Nova York: Basic Books; 1979.

2. Sandison RA. LSD therapy: a retrospective. In: Melechi A. Psychedelia Britannica: hallucinogenic drugs in Britain. Londres: Turnover; 1997. p. 53-76.

3. Pahnke WN, Richards WA. Implications of LSD and experimental mysticism. In: Tart CT, editor. Altered states of consciousness: a book of readings. Nova York: Garden City; 1972. p. 276-96.

4. Grinker R. Lysergic acid diethylamide. Arch Gen Psychiatry. 1963;8(5):425.
5. Cole JO, Katz M. The psychotomimetic drugs. JAMA. 1964;187:182-5.

6. Controlled Substance Act (CSA) 2000. 84 Stat. 1242 as amended 1 U.S.C. (2000 Ed. And Supp. 1); 801-904.

7. Grob CS. Psychiatric research with hallucinogens: what have we learned? Heffter Rev Psychedelic Res. 1998;(1):8-20.

8. Griffiths RR, Grob CS. Hallucinogens as medicine. Sci Am. 2010;303:77-9.

9. Moreno FA, Wiegand CB, Taitano EK, Delgado PL. Safety, tolerability, and efficacy of psilocybin in 9 patients with obsessive-compulsive disorder J Clin Psychiatry. 2006;67(11):1735-40.

10. Grob CS, Danforth AL, Chopra GS, Hagerty M, McKay CR, Halberstadt AL, et al. Pilot study of psilocybin treatment for anxiety in patients with advanced-stage cancer. Arch Gen Psychiatry. 2011;68(1):71-8.

11. Berman RM, Cappiello A, Anand A, Oren DA, Heninger GR, Charney DS, et al. Antidepressant effects of ketamine in depressed patients. Biol Psychiatry. 2000;47:351-4.

12. Krupitsky E, Burakov A, Romanova T, DunaesskyI, Strassman RJ, Grinenko A. Ketamine psychotherapy for heroin addiction: immediate effects and two-year follow-up. J Subst Abuse Treat. 2002;23(4):273-83.

13. Griffiths RR, Richards WA, McCann U, Jesse R. Psilocybin can occasion mystical-type experiences having substantial and sustained personal meaning and spiritual significance. Psychopharmacol. 2006;187(3):268-83.

14. Griffiths RR, Richards W, Johnson M, McCann U, Jesse R. Mystical-type experiences occasioned by psilocybin mediate the attribution of personal meaning and spiritual significance 14 months later. J Psychopharmacol. 2008;22:621-32.

15. CONAD 2006: Conselho Nacional Antidrogas. Grupo Multidisciplinar de Trabalho - GMT - Ayahuasca: Relatório Final. Disponível em $<$ http://www.ayahuascabrasil.org/index.php?op=noticia010 $>$. Acesso em: 26 jun. 2010.

16. Conselho Federal de Entorpecentes (CONFEN). Resolução no 6 CONFEN. 1986. Disponível em: <http://www.ayahuascabrasil.org >. Acesso em: 9 mar. 2011.

17. MacRae E. Guiado pela lua: xamanismo e o uso ritual da ayahuasca no culto do Santo Daime. São Paulo: Brasiliense; 1992.

18. Moreira A, Pinsky I, Zaleski M, Laranjeira R. Envolvimento religioso e fatores sociodemográficos: resultados de um levantamento nacional no Brasil. Rev Psiq Clín. 2010;37(1):12-5.

19. Queiroz S, Scivoletto S, Silva MMS, Strassman PG, Andrade AG, Gattaz WF. Uso de drogas entre estudantes de uma escola pública de São Paulo. Rev Psiq Clín. 2001;28(4):176-82.

20. Strassman R. DMT - the spirit molecule, a doctor's revolutionary research into the biology of near-death and mystical experiences. South Paris, ME: Park Street Press; 2001.

21. Strassman RJ, Qualls CR, Uhlenhuth EH, Kellner R. Dose-response study of N,N-dimethyltryptamine in humans. II. Subjective effects and preliminary results of a new rating scale. Arch Gen Psychiatry. 1994;51:98-108.

22. Strassman RJ, Qualls CR, Uhlenhuth EH, Kellner R. Dose-response study of N,N-dimethyltryptamine in humans. II. Subjective effects and preliminary results of a new rating scale. Arch Gen Psychiatry. 1994;51:98-108 (Appendix, disponibilizado pelo autor).

23. Riba J, Rodríguez-Fornells A, Strassman RJ, Barbanoj MJ. Psychometric assessment of the Hallucinogen Rating Scale. Drug Alcohol Depend. 2001;62:215-23.

24. Lamas X, Farre' M, Llorente M, Camı' J. Spanish version of the 49-item short form of the Addiction Research Center Inventory (ARCI). Drug Alcohol Depend. 1994b;35:203-9.

25. Riba J, Rodríguez-Fornells A, Urbano G, Morte A, Antonijoan R, Montero RAM, et al. Subjective effects and tolerability of the South American psychoactive beverage ayahuasca in healthy volunteers. Psychopharmacol. 2001;154:85-95.

26. Riba J, Valle M, Urbano G, Yritia M, Morte A, Barbanoj MJ. Human pharmacology of Ayahuasca: subjective and cardiovascular effects, monoamine metabolite excretion and pharmacokinetics. J Pharmacol Exp Ther. 2003;306:73-83.

27. Rocha NS, Fleck MPA. Avaliação de qualidade de vida e importância dada a espiritualidade/religiosidade/crenças pessoais (SRPB) em adultos com e sem problemas crônicos de saúde. Rev Psiq Clín. 2011;38(1):19-23.

28. Almeida AM, Lotufo Neto F. Diretrizes metodológicas para investigar estados alterados de consciência e experiências anômalas. Rev Psiq Clín. 2003;30(1). Disponível em: <http://www.scielo.br/scielo.php?script=sci_ arttext\&pid=S0101-60832003000100003\&lng=pt\&nrm=iso $>$. Acesso em: 15 ago. 2011. http://dx.doi.org/10.1590/S0101-60832003000100003.

29. Guillemin F. Cross-cultural adaptation and validation of health status measures. Scand J Rheumatol. 1995;24(2):61-3. 


\section{ANEXO I - HALLUCINOGEN RATING SCALE HRS (Version 3.06P)}

Abaixo estão listadas afirmações referentes aos efeitos experimentados durante a sua última experiência. Para cada afirmação, marque a resposta que mais corresponda ao efeito mais intenso experimentado por você. Este questionário é a respeito do que você vivenciou ao longo de todo o processo. Marque apenas uma resposta para cada item; marque o que parece ser melhor, mesmo se nenhuma resposta corresponder ao que você sentiu exatamente. Não se preocupe se, algumas vezes, sua resposta entrar em contradição com respostas anteriores, ou se duas sensações diferentes ocorreram ao mesmo tempo. Marque sempre de acordo com o que você sentiu a cada vez.

Nome

Experiência do dia ___ _ _ _

Data do preenchimento da Escala: __________

Copyright@ 1994, by Rick J. Strassman, M.D., Department of Psychiatry, University of New Mexico, School of Medicine, Albuquerque, NM. All rights reserved. No part of this instrument may be used or reproduced in any manner whatsoever without written permission of the author.

\begin{tabular}{|c|c|c|c|c|c|c|c|c|}
\hline \multirow{2}{*}{\begin{tabular}{|l}
1. \\
2.
\end{tabular}} & \multicolumn{2}{|c|}{$\begin{array}{l}\text { Tempo decorrido entre a administração e a experiência de seu } \\
\text { efeito? }\end{array}$} & \multirow{2}{*}{\begin{tabular}{|l}
$\begin{array}{l}\text { Não aplicável } \\
\text { Sem efeito }\end{array}$ \\
nenhum
\end{tabular}} & \multirow{2}{*}{\begin{tabular}{|l|l|} 
& $0-5$ minutos \\
\end{tabular}} & \multirow{2}{*}{\begin{tabular}{|l|l|} 
& 5-15 minutos \\
Moderadamente
\end{tabular}} & \multirow{2}{*}{\begin{tabular}{|l|l|} 
& $15-30$ minutos \\
Muito
\end{tabular}} & \multirow{2}{*}{ 30-60 minutos } & \multirow{2}{*}{\begin{tabular}{|l|l|}
$\begin{array}{l}\text { Mais de uma } \\
\text { hora }\end{array}$ \\
Extremamente
\end{tabular}} \\
\hline & $\begin{array}{l}\text { Como você sentiu a rapidez e a força dos efeitos } \\
\text { chegando? }\end{array}$ & De mod & & & & & & \\
\hline 2a. & \multicolumn{8}{|l|}{$\begin{array}{l}\text { Houve alguma localização dos efeitos experimentados? } \\
\text { Descreva, por favor. }\end{array}$} \\
\hline 3. & Mudança na salivação? & \multicolumn{2}{|c|}{ De modo nenhum } & Levemente & Moderadamente & \multicolumn{2}{|l|}{ Muito } & Extremamente \\
\hline 3a. & Secura, mais salivação, ou ambas. (Circule um.) & & & & & & & \\
\hline 4. & Sentiu o corpo ou alguma parte dele diferente? & \multicolumn{2}{|c|}{ De modo nenhum } & Levemente & Moderadamente & \multicolumn{2}{|l|}{ Muito } & Extremamente \\
\hline 4a. & Descreva, por favor. & & & & & & & \\
\hline 5. & $\begin{array}{l}\text { Sentiu alguma mudança na percepção de peso do seu } \\
\text { corpo? }\end{array}$ & \multicolumn{2}{|c|}{ De modo nenhum } & Levemente & Moderadamente & \multicolumn{2}{|l|}{ Muito } & Extremamente \\
\hline 5a. & \multicolumn{8}{|l|}{ Mais leves, mais pesados, ou ambos. (Circule um.) } \\
\hline 6. & $\begin{array}{l}\text { Você se sentiu como em movimento, caindo ou } \\
\text { voando pelo espaço? }\end{array}$ & \multicolumn{2}{|c|}{ De modo nenhum } & Levemente & Moderadamente & \multicolumn{2}{|l|}{ Muito } & Extremamente \\
\hline 7. & $\begin{array}{l}\text { Sentiu alguma mudança na temperatura de seu } \\
\text { corpo? }\end{array}$ & \multicolumn{2}{|c|}{ De modo nenhum } & Levemente & Moderadamente & \multicolumn{2}{|l|}{ Muito } & Extremamente \\
\hline 7a. & \multicolumn{8}{|l|}{ Mais quente ou com calor, mais frio, ou ambos. (Circule um.) } \\
\hline 8. & $\begin{array}{l}\text { Você sentiu agulhadas/alfinetadas e/ou uma pequena } \\
\text { sensação elétrica/eletricidade? }\end{array}$ & \multicolumn{2}{|c|}{ De modo nenhum } & Levemente & Moderadamente & \multicolumn{2}{|l|}{ Muito } & Extremamente \\
\hline 9. & Pressão ou peso dentro do peito ou na barriga? & \multicolumn{2}{|c|}{ De modo nenhum } & Levemente & Moderadamente & \multicolumn{2}{|l|}{ Muito } & Extremamente \\
\hline 9a. & Fisicamente solto, ágil ou flexível? & De mod & enhum & Levemente & Moderadamente & Muito & & Extremamente \\
\hline 10. & $\begin{array}{l}\text { Ficou com a impressão de estar "tremendo por } \\
\text { dentro" (tremores internos)? }\end{array}$ & De mod & רenhum & Levemente & Moderadamente & Muito & & Extremamente \\
\hline 11. & Sentiu o corpo sacudindo, tremendo? & De mod & nenhum & Levemente & Moderadamente & Muito & & Extremamente \\
\hline 12. & Sentiu o coração batendo? & De mod & רenhum & Levemente & Moderadamente & Muito & & Extremamente \\
\hline 13. & Sentiu o coração batendo irregularmente? & De mod & enhum & Levemente & Moderadamente & Muito & & Extremamente \\
\hline 14. & Náusea ou enjoo? & De mod & רenhum & Levemente & Moderadamente & Muito & & Extremamente \\
\hline 15. & Fisicamente confortável? & De mod & רenhum & Levemente & Moderadamente & Muito & & Extremamente \\
\hline 16. & Fisicamente inquieto? & De mod & enhum & Levemente & Moderadamente & Muito & & Extremamente \\
\hline 17. & Você se sentiu ruborizado ou corado? & De mod & רenhum & Levemente & Moderadamente & Muito & & Extremamente \\
\hline 18. & Com vontade de urinar? & De mod & רenhum & Levemente & Moderadamente & Muito & & Extremamente \\
\hline 19. & Vontade de defecar (fazer cocô)? & De mod & enhum & Levemente & Moderadamente & Muito & & Extremamente \\
\hline 20. & Sensações sexuais? & De mod & רenhum & Levemente & Moderadamente & Muito & & Extremamente \\
\hline 21. & $\begin{array}{l}\text { Você se sentiu afastado, destacado ou deslocado do } \\
\text { corpo? }\end{array}$ & De mod & enhum & Levemente & Moderadamente & Muito & & Extremamente \\
\hline 22. & Houve mudança na sensibilidade da sua pele? & De mod & רenhum & Levemente & Moderadamente & Muito & & Extremamente \\
\hline 22a. & Mais sensível, menos sensível, ou ambos. (Circule um.) & & & & & & & \\
\hline 23. & Você suou? & De mod & רenhum & Levemente & Moderadamente & Muito & & Extremamente \\
\hline 24. & Sentiu dor de cabeça? & De mod & רenhum & Levemente & Moderadamente & Muito & & Extremamente \\
\hline 25. & Ficou ansioso? & De mod & רenhum & Levemente & Moderadamente & Muito & & Extremamente \\
\hline 26. & Você se sentiu assustado? & De mod & רenhum & Levemente & Moderadamente & Muito & & Extremamente \\
\hline 27. & Sentiu pânico? & De mod & רenhum & Levemente & Moderadamente & Muito & & Extremamente \\
\hline $27 a$. & $\begin{array}{l}\text { Você experimentou um sentimento de autoaceitação? } \\
\text { (estando menos crítico em relação a si mesmo?). }\end{array}$ & De mod & enhum & Levemente & Moderadamente & Muito & & Extremamente \\
\hline 28. & Você se sentiu à vontade? & De mod & רenhum & Levemente & Moderadamente & Muito & & Extremamente \\
\hline 28 . & Perdoando a si mesmo ou aos outros? & De mod & רenhum & Levemente & Moderadamente & Muito & & Extremamente \\
\hline 29. & Com vontade de rir? & De mod & nenhum & Levemente & Moderadamente & Muito & & Extremamente \\
\hline 30. & Você se sentiu animado, disposto, entusiasmado? & De mod & רenhum & Levemente & Moderadamente & Muito & & Extremamente \\
\hline
\end{tabular}




\begin{tabular}{|c|c|c|c|c|c|c|c|}
\hline 31. & $\begin{array}{l}\text { Você se sentiu em estado de reverência ou em } \\
\text { deslumbramento? }\end{array}$ & De modo nenhum & Levemente & Moderadamente & \multicolumn{2}{|l|}{ Muito } & Extremamente \\
\hline $31 \mathrm{a}$. & $\begin{array}{l}\text { Sentiu que estava compreendendo os sentimentos } \\
\text { dos outros? }\end{array}$ & De modo nenhum & Levemente & Moderadamente & \multicolumn{2}{|l|}{ Muito } & Extremamente \\
\hline 32. & Você se sentiu em segurança? & De modo nenhum & Levemente & Moderadamente & \multicolumn{2}{|l|}{ Muito } & Extremamente \\
\hline 33. & $\begin{array}{l}\text { Sentiu a presença de uma força numinosa, de um } \\
\text { poder superior, de Deus? }\end{array}$ & De modo nenhum & Levemente & Moderadamente & \multicolumn{2}{|l|}{ Muito } & Extremamente \\
\hline 34. & $\begin{array}{l}\text { Você sentiu uma mudança no modo pelo qual você } \\
\text { respondia "emocionalmente" (sentiu/experimentava) } \\
\text { aos sons? }\end{array}$ & De modo nenhum & Levemente & Moderadamente & \multicolumn{2}{|l|}{ Muito } & Extremamente \\
\hline \multicolumn{8}{|c|}{ 34a. Mudança mais agradável, menos agradável, ou ambas. (Circule um.) } \\
\hline 35. & Você se sentiu feliz? & De modo nenhum & Levemente & Moderadamente & \multicolumn{2}{|l|}{ Muito } & Extremamente \\
\hline & Triste? & De modo nenhum & Levemente & Moderadamente & \multicolumn{2}{|l|}{ Muito } & Extremamente \\
\hline 36a. & Você se sentiu "cheio de amor"? & De modo nenhum & Levemente & Moderadamente & \multicolumn{2}{|l|}{ Muito } & Extremamente \\
\hline 37. & Ficou eufórico? & De modo nenhum & Levemente & Moderadamente & \multicolumn{2}{|l|}{ Muito } & Extremamente \\
\hline 38. & Desesperado? & De modo nenhum & Levemente & Moderadamente & \multicolumn{2}{|l|}{ Muito } & Extremamente \\
\hline 39. & Com vontade de chorar? & De modo nenhum & Levemente & Moderadamente & \multicolumn{2}{|l|}{ Muito } & Extremamente \\
\hline 40. & $\begin{array}{l}\text { Você sentiu mudança em relação a sua sensação de } \\
\text { proximidade/intimidade para com as pessoas ali do } \\
\text { ambiente? }\end{array}$ & De modo nenhum & Levemente & Moderadamente & \multicolumn{2}{|l|}{ Muito } & Extremamente \\
\hline \multicolumn{8}{|c|}{ 40a. Mais próximas, menos próximas, ou ambas. (Circule um.) } \\
\hline 41. & $\begin{array}{l}\text { Você sentiu mudança na quantidade das suas } \\
\text { emoções? }\end{array}$ & De modo nenhum & Levemente & Moderadamente & \multicolumn{2}{|l|}{ Muito } & Extremamente \\
\hline \multicolumn{8}{|c|}{ 41a. Mais emotivo, menos emotivo, ou ambos. (Circule um.) } \\
\hline 42. & As emoções pareciam diferentes das habituais? & De modo nenhum & Levemente & Moderadamente & \multicolumn{2}{|l|}{ Muito } & Extremamente \\
\hline 43. & Você sentiu estar em unidade com o universo? & De modo nenhum & Levemente & Moderadamente & \multicolumn{2}{|l|}{ Muito } & Extremamente \\
\hline 44. & Você se sentiu isolado das pessoas e coisas? & De modo nenhum & Levemente & Moderadamente & \multicolumn{2}{|l|}{ Muito } & Extremamente \\
\hline 45. & Você se sentiu renascido? & De modo nenhum & Levemente & Moderadamente & \multicolumn{2}{|l|}{ Muito } & Extremamente \\
\hline 46. & Ficou satisfeito com a experiência? & De modo nenhum & Levemente & Moderadamente & \multicolumn{2}{|l|}{ Muito } & Extremamente \\
\hline 47. & Gostou da experiência? & De modo nenhum & Levemente & Moderadamente & \multicolumn{2}{|l|}{ Muito } & Extremamente \\
\hline 48. & $\begin{array}{l}\text { Daqui a quanto tempo você gostaria de repetir a } \\
\text { experiência? }\end{array}$ & Nunca mais & $\begin{array}{l}\text { Dentro de um } \\
\text { ano }\end{array}$ & Dentro de um mês & Dentro de uma ser & & $\begin{array}{l}\text { Logo que } \\
\text { possivel }\end{array}$ \\
\hline 49. & Deseja a experiência regularmente? & De modo nenhum & Levemente & Moderadamente & Muito & & Extremamente \\
\hline 50. & Sentiu algum cheiro? & De modo nenhum & Levemente & Moderadamente & Muito & & Extremamente \\
\hline 50a. & Por favor, descreva. & & & & & & \\
\hline 51. & Sentiu algum sabor, gosto de algo? & De modo nenhum & Levemente & Moderadamente & Muito & & Extremamente \\
\hline 51a. & Por favor, descreva. & & & & & & \\
\hline 52. & Ouviu um som ou sons acompanhando a experiência? & De modo nenhum & Levemente & Moderadamente & Muito & & Extremamente \\
\hline 52a. & Por favor, descreva. & & & & & & \\
\hline 53. & $\begin{array}{l}\text { Viveu uma sensação de silêncio ou profunda } \\
\text { quietude? }\end{array}$ & De modo nenhum & Levemente & Moderadamente & Muito & & Extremamente \\
\hline 54. & Os sons soavam diferentes no ambiente? & De modo nenhum & Levemente & Moderadamente & Muito & & Extremamente \\
\hline 55. & Houve alteração na distinção (clareza) dos sons? & De modo nenhum & Levemente & Moderadamente & Muito & & Extremamente \\
\hline $55 a$. & Mais claros, menos claros, ou ambos. (Circule um.) & & & & & & \\
\hline 56. & $\begin{array}{l}\text { Você teve sinestesia auditiva ("ouvir" visualmente - } \\
\text { audição visual, ou outras percepções não auditivas). }\end{array}$ & De modo nenhum & Levemente & Moderadamente & Muito & & Extremamente \\
\hline 57. & Efeitos visuais? & De modo nenhum & Levemente & Moderadamente & Muito & & Extremamente \\
\hline & Visualmente, a sala pareceu diferente? & Não sei, olhos fechados & $\begin{array}{l}\text { De modo } \\
\text { nenhum }\end{array}$ & Levemente & Moderadamente & Muito & Extremamente \\
\hline 59. & $\begin{array}{l}\text { Os objetos da sala tinham um brilho diferente do } \\
\text { habitual? }\end{array}$ & Não sei, olhos fechados & $\begin{array}{l}\text { De modo } \\
\text { nenhum }\end{array}$ & Levemente & Moderadamente & Muito & Extremamente \\
\hline & Mais brilhantes, menos brilhantes, ou ambos. (Circule & um.) & & & & & \\
\hline 60. & $\begin{array}{l}\text { Houve mudança na discriminação visual dos objetos } \\
\text { do ambiente? }\end{array}$ & Não sei, olhos fechados & $\begin{array}{l}\text { De modo } \\
\text { nenhum }\end{array}$ & Levemente & Moderadamente & Muito & Extremamente \\
\hline 60a. & Mais nítidos, borrados, ou ambos. (Circule um.) & & & & & & \\
\hline 61. & 0 ambiente estava recoberto com padrões visuais? & Não sei, olhos fechados & $\begin{array}{l}\text { De modo } \\
\text { nenhum }\end{array}$ & Levemente & Moderadamente & Muito & Extremamente \\
\hline 62. & $\begin{array}{l}\text { Com olhos abertos, o campo visual ficava vibrando ou } \\
\text { saracoteando (sacudindo)? }\end{array}$ & Não sei, olhos fechados & $\begin{array}{l}\text { De modo } \\
\text { nenhum }\end{array}$ & Levemente & Moderadamente & Muito & Extremamente \\
\hline 63. & $\begin{array}{l}\text { Sinestesia visual ("vendo" sons ou outra percepção } \\
\text { não visual)? }\end{array}$ & De modo nenhum & Levemente & Moderadamente & Muito & Extremamente & \\
\hline 64. & $\begin{array}{l}\text { Você teve imagens visuais, visões, alucinações } \\
\text { (podendo incluir apenas padrões geométricos } \\
\text { abstratos) }\end{array}$ & De modo nenhum & Levemente & Moderadamente & Muito & Extremamente & \\
\hline 65. & $\begin{array}{l}\text { As imagens, visões e alucinações eram de natureza } \\
\text { caleidoscópica? }\end{array}$ & Não aplicável. Nada visto. & $\begin{array}{l}\text { De modo } \\
\text { nenhum }\end{array}$ & Levemente & Moderadamente & Muito & Extremamente \\
\hline
\end{tabular}


66. Houve diferença no brilho das cores das imagens/ visões comparadas com a visão à luz do dia cotidiana?

\begin{tabular}{|l|l|l}
\hline Não aplicável. Nada visto. & $\begin{array}{l}\text { De modo } \\
\text { nenhum }\end{array}$ & Levemente \\
\hline
\end{tabular}

\begin{tabular}{|l|l}
\hline Moderadamente & Muito
\end{tabular}

Extremamente

66a. Cores mais brilhantes, menos brilhantes ou ambas. (Circule um.)

66b. Cores predominantes

67. Qual a dimensão das imagens/visões/ alucinações?

\begin{tabular}{|l|}
\hline Não \\
aplicável. \\
Nada visto
\end{tabular}

68. Houve movimento nas visões, alucinações?
Linear (unidimensional)

Não aplicável. Nada visto.

\begin{tabular}{|l|}
\hline \\
De modo \\
nenhum
\end{tabular}

68a. Por favor, descreva as visões, alucinações.

69. Houve a percepção de uma luz branca?

70. Você se sentiu como se estivesse morto ou morrendo?

71. Teve sensação de velocidade?

72. Teve a impressão de já ter vivido uma determinada situação que você nunca viveu? (Totalmente desconhecida, sem memória real disso, mas acha que já viveu aquilo antes, como uma experiência muito familiar.)

73. Você teve a sensação de, diante de uma situação que lhe é familiar, de repente, naquele momento, tivesse se tornado totalmente estranha, desconhecida, não familiar?

74. Você viveu sentimentos contraditórios ao mesmo tempo (alegre e triste, ou esperançoso e sem esperança)?

75. Sensação de caos?

\begin{tabular}{|l|l}
\hline De modo nenhum \\
\hline De modo nenhum \\
\hline De modo nenhum \\
\hline De modo nenhum \\
\end{tabular}

De modo nenhum

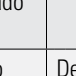

De modo nenhum

76. Você sentiu uma mudança na percepção de "como você é"? De modo nenhum

76a. Mais fortemente, menos fortemente, ou ambos. (Circule um.)

77. Teve novos pensamentos ou insights/revelações, ideias
novas?

78. Memórias, lembranças da infância?

79. Sentiu-se como uma criança?

80. Houve alteração na velocidade do pensamento?

80a. Mais rápido, mais lento, ou ambos. (Circule um.)

81. Houve mudança na qualidade de seu pensamento?

\begin{tabular}{|c|c|}
\hline Levemente & 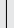 \\
\hline Levemente & 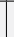 \\
\hline Levemente & \\
\hline Levemente & \\
\hline
\end{tabular}

Levemente

Levemente

Levemente

Levemente

De modo nenhum

\begin{tabular}{|l|l|}
\hline Levemente & Mod \\
\hline Levemente & Mod \\
\hline Levemente & Mod \\
\hline Levemente & Mod \\
\hline
\end{tabular}

De modo nenhum

De modo nenhum

Levemente

\begin{tabular}{|l|l|l|l|}
\hline $\begin{array}{l}\text { Superfície plana } \\
\text { (duas dimensões) }\end{array}$ & Tridimensional & Multidimensional & $\begin{array}{l}\text { Além da } \\
\text { dimensão }\end{array}$ \\
\hline Levemente & Moderadamente & Muito & Extremamente \\
\hline
\end{tabular}

Moderadamente

Moderadamente

Moderadamente

Muito

Extremamente

Extremamente

Moderadamente Muito

Extremamente

Moderadamente

Moderadamente

Muito

Extremamente

Moderadamente

Moderadamente

Moderadamente

Muito

Extremamente

Moderadament

Moderadamente

Moderadamente

Moderadamente

Muito

Extremamente

Extremamente

81a. Pensamento mais aguçado/agudo, menos aguçado, ou ambos. (Circule um.)

82. Houve diferença na sensação de realidade das experiências $\quad$ De modo nenhum quando comparadas às experiências de seu dia a dia?

82a. Pareciam mais reais, menos reais, ou ambos. (Circule um.)

83. Houve experiências de natureza onírica, como um sonho? $\quad$ De modo nenhum

84. Houve pensamentos de sua vida pessoal atual, ou de um $\quad$ De modo nenhum passado recente?

\begin{tabular}{|l|l|l}
\hline 85. Houve insights, descobertas novas, revelações em relação & De modo nenhum
\end{tabular} a assuntos pessoais ou profissionais?

86. Houve variação na velocidade do tempo passar?

De modo nenhum

Moderadamente

Muito

Extremamente

Extremamente

Extremamente

Extremamente

86a. Passando mais rápido, mais lento, ou ambos. (Circule um.)

87. Ficou sem consciência daquilo que acontecia?

Definitivamente não

Levemente

Moderadamente

\begin{tabular}{|l} 
Muito \\
Muito
\end{tabular}

Muito

Muito

Extremamente

87. Ficou sem consciencia daquilo que acontecia?

88. Houve mudança em sua impressão de sanidade mental?

De modo nenhum

\begin{tabular}{|l|l|}
\hline Levemente \\
\hline Levemente \\
\hline Levemente \\
\hline Levemente
\end{tabular}

Moderadamente

Extremamente

88a. Mentalmente mais são, mentalmente menos são, ou ambos. (Circule um.)

89. Teve necessidade de fechar os olhos?

90. Houve mudança no esforço para você respirar?

\begin{tabular}{|l|l|l} 
90a. Respirando de forma mais relaxada, mais dificultada, ou ambos. (Circule um.) \\
\hline 91. Você se sentiu capaz de seguir a sequência dos eventos? & De modo nenhum
\end{tabular}

92. Foi capaz de se soltar, deixar acontecer? $\quad$ De modo nenhum

93. Capaz de focalizar a atenção?

94. Você foi capaz de controlar a si mesmo e a situação (sob $\quad$ De modo nenhum controle)?

95. Seria capaz de se locomover, caso lhe pedissem?

96. Seria capaz de se lembrar de que estava sob o efeito de $\quad$ De modo nenhum uma substância, da natureza temporária da experiência?

97. Você sentiu que havia ondas repetitivas de ascensão e de declínio (efeitos da substância) na qualidade de sua experiência ao longo do processo?

98. Qual foi a intensidade?

99. Sentiu-se "ligado" (ou seja, estar sob o efeito de uma substância, com um estado alterado de consciência)?

100. Você acha que tomou placebo?

Moderadamente

Moderadamente

Moderadamente

Muito Extrer

Extremamente

Extremamente

Muito

Extremamente

Muito

Extremamente

\begin{tabular}{|l|l} 
Não tenho & Definitivamente sim
\end{tabular}

certeza

\begin{tabular}{l|l} 
Moderadamente & Muito
\end{tabular}

Extremamente

Algum outro comentário?

De modo nenhum De modo nenhum

De modo nenhum

De modo nenhum

\begin{tabular}{l|l} 
De modo nenhum & Levemente
\end{tabular}

De modo nenhum

\section{Levemente}

Levemente

Levemente

Levemente

Levemente

Levemente

Levemente

Levemente

Levement

De modo nenhum

De modo nenhum

Sim

Levemente

Levemente
Moderadamente $\quad$ Muito

Moderadamente Muito

\begin{tabular}{l|l} 
Moderadamente & Muito
\end{tabular}

Moderadamente Muito

Moderadamente Muito

Moderadamente Muito

Moderadamente

Moderadamente

Muito

Muito

Moderadamente

Muito

Moderadamente

\begin{tabular}{l|l} 
Moderadamente & Muito \\
\hline Moderadamente & Muito
\end{tabular}

Muito

Não
Extremamente

Extremamente

Extremamente

Extremamente

Extremamente

Extremamente

Extremamente

Extremamente

Extremamente

Extremamente

Extremamente 
1. Errata do artigo: “Delirium: uma perspectiva histórica” publicado em 2005;32(3):97-103.

No resumo, a segunda e a terceira frase devem ser substituídas pelo texto seguinte:

Segundo Berrios (1981), no final do século XIX o conceito de delirium passou a levar em conta não apenas seus aspectos fenomenológicos, mas também os seus distintos fatores etiológicos. Isso ampliou a abrangência da definição dos "estados confusionais", enfatizando que a desorganização dos processos cognitivos e do pensamento é consequência do turvamento da consciência e da desorientação temporoespacial.

2. Errata do artigo: “Hallucinogen Rating Scale (HRS) - Versão brasileira: tradução e adaptação transcultural” publicado em 2011;38(6):231-7.

Na página 235 no ANEXO I - HALLUCINOGEN RATING SCALE HRS (Version 3.06P)

Na Questão 7, onde se lê: “De modo nenhum, Levemente, Moderadamente, Muito”, deve-se acrescentar o último item: “Extremamente”.

Na Questão 63, onde se lê: “cinestesia”, deve-se ler: "sinestesia”.

$\mathrm{Na}$ Questão 66.b, onde se lê: “Cores predominantes”, devem-se retirar os traços, pois o espaço é destinado à resposta da descrição das cores.

$\mathrm{Na}$ Questão 73, onde se lê: "Você teve a sensação de, diante de uma situação que lhe é familiar, de repente, naquele momento tivesse se tornado totalmente estranho, desconhecido, não familiar?", deve-se ler: "Você teve a sensação de, diante de uma situação que lhe é familiar, de repente, naquele momento, tivesse se tornado totalmente estranha, desconhecida, não familiar?". 